REVISTA CIENCIAS BIOMÉ DICAS

PRESENTACIÓN DE CASOS CLÍNICOS

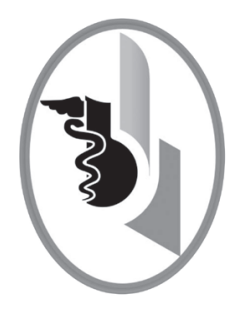

\title{
ACROCORDÓN ULCERADO EN VULVA
}

\author{
ULCERATED ACROCHORDON IN VULVA
}

Borré-Arrieta Orlando ${ }^{1}$

Monsalve-Montoya Rosa²

Correspondencias: remm0501@hotmail.com

Recibido para evaluación: agosto-24-2014. Aceptado para publicación: marzo-29-2015.

\section{RESUMEN}

Introducción: el acrocordón ( $A C)$, también conocido como fibroma laxo, es una patología dermatológica de común ubicación en los pliegues del cuerpo. Su aparición en genitales externos es rara, pero genera consecuencias negativas en cuanto a la calidad de vida de las pacientes. Por las características propias de la zona genital en las mujeres, aumenta el riesgo de ulceración y sobreinfección.

Caso clínico: paciente en la tercera década de la vida, con lesión de lento crecimiento en región vulvar, que acudió tardíamente al servicio de urgencias por presentar laceración y signos de infección en la lesión genital.

Conclusión: el AC de vulva o pólipo fibroepitelial vulvar es una patología, benigna y poco frecuente, no obstante siempre amerita tratamiento oportuno, tanto por razones estéticas como por el riesgo de ulceraciones. Revista ciencias biomédicas. 2015;6(1):138-141

PALABRAS CLAVE

Vulva; Enfermedades de la vulva; Neoplasias de la vulva.

\section{SUMMARY}

Introduction: the acrochordon, also known as soft fibromas, is a dermatological disease of common location in the cutaneous folds. Its appearance in external genitalia is weird, but it generates negative consequences regarding the quality of life of the patients. Due to the typical characteristics of the genital area in women, it increases the risk of ulceration and superinfection.

Case record: patient in the third decade of life with lesion of slow growth in the vulvar area, who attended late to the emergency service because of the presence of laceration and infection signs in the genital lesion.

Conclusions: the acrochordon in vulva or vulvar fibroma is a vulvar benign and uncommon disease, however it always merits opportune treatment by esthetic reason as for the ulceration risk. Revista ciencias biomédicas. 2015;6(1):138-141

\section{KEYWORDS}

Vulva; Vulvar diseases; Vulvar neoplasms.

1 Médico. Especialista en Ginecología y Obstetricia. Docente Departamento de Ginecología y Obstetricia. Facultad de Medicina. Universidad de Cartagena. Colombia.

2 Médico. Estudiante de Postgrado. Ginecología y Obstetricia. Facultad de Medicina. Universidad de Cartagena. Colombia 


\section{INTRODUCCIÓN}

La patología vulvar benigna es uno de los motivos de consulta ginecológica más frecuentes. Los trastornos vulvares suelen producir disfunción sexual y alteran la imagen corporal. Por tal razón, un manejo adecuado de las pacientes que consultan al ginecólogo es dar un efecto positivo en estos aspectos, mejorando de manera significativa la calidad de vida (1).

El acrocordón ( $A C$ ) es una patología de ubicación vulvar poco común, de características benignas, pero que debido al crecimiento, fricción, torsión o a factores propios de esa localización, como calor y humedad, puede estar predispuesta a morbilidades secundarias (1). El objetivo es presentar un caso de AC atendido de forma tardía.

\section{CASO CLÍNICO}

Paciente femenina de 32 años de edad, sin hijos ni embarazos previos. Menarca a los 12 y vida marital a los 19 años. Ciclos menstruales de 30/4. Refirió cuadro clínico de diez meses de evolución, con presencia de masa en genitales externos, la cual lentamente fue aumentando de tamaño, sin ser dolorosa. En los diez días previos a la consulta, la lesión se tornó eritematosa y pruriginosa, presentándose pérdida de continuidad en la piel y aparición de secreción serosa. Simultáneamente comenzó a presentar fiebre subjetiva, haciéndose más marcada en los dos días anteriores a la consulta.

La paciente negó actividad sexual desde hacía más de cinco años, por lo cual no utilizaba métodos de planificación. Negó trauma, pérdida de peso o vómito. Tampoco informó acerca de otras patologías, negó antecedentes personales de infecciones de transmisión sexual o familiares de cáncer.

Al examen físico se encontró paciente es buenas condiciones generales, hidratada, con PA: 110/74 mm/Hg, FC: 88 Ipm, FR: 18 rpm, Temperatura $36,2^{\circ} \mathrm{C}$. En la valoración ginecológica se encontró una masa grande, con pediculo entorchado, blanda, con base estrecha en la cara externa del labio mayor derecho. Tamaño $11 \times 8 \mathrm{~cm}$, normocrómica, con úlceras de la piel que recubría la lesión, de bordes necróticos hacia la base y secreción serosa fétida, escasa. No se identificaron signos de rascado (Figura No 1 ).

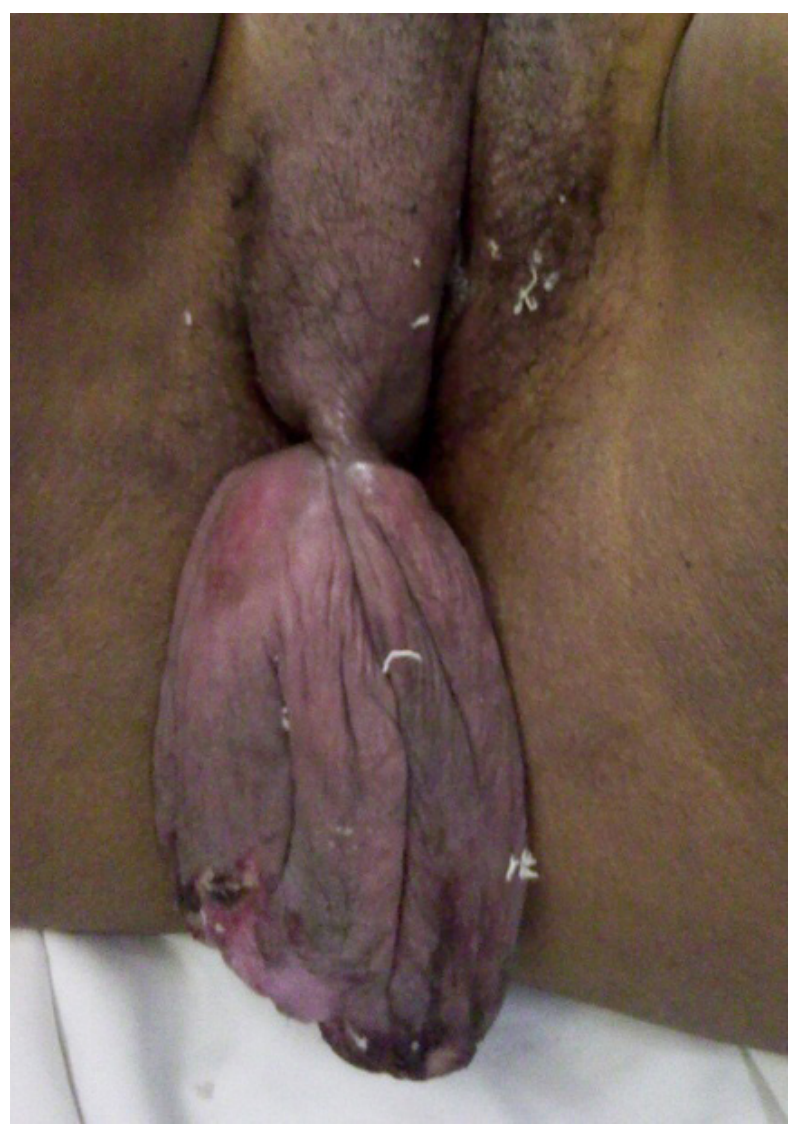

Figura $\mathbf{N}^{\circ}$ 1. Acrocordón, lesión pediculada en genitales externos. Obsérvese la torsión en la base de la lesión.

No fueron palpables adenopatías inquinales ni las glándulas de Bartolino, tampoco se encontraron otras lesiones satélites a nivel vulvar, inguinal o perineal. A la especuloscopia se observaron paredes vaginales normales, sin lesiones y cuello uterino de aspecto sano. Al tacto vaginal se encontró útero y anexos de tamaño normal, sin dolor al examen ni masas pélvicas. Se realizó impresión clínica de AC con ulceración e infección secundaria. Para realizar el acto operatorio y extirpar la lesión, se ordenó hemograma, PCR, plaquetas y pruebas de coagulación, las cuales fueron realizadas sin que se encontraran anormalidades.

Se realizó resección quirúrgica de la lesión seccionado la base, bajo anestesia general. La Figura No 2 presenta la pieza operatoria. 
Se envió toda la lesión para estudio histopatológico y se hospitalizó a la paciente para manejo con antibióticos intravenosos, por los signos locales de infección. Tres días después se dio de alta con buena recuperación posoperatoria y con orden de continuar los antibióticos por vía oral para cumplir los diez días de tratamiento. Dos semanas después fue valorada estando en buenas condiciones con cicatrización satisfactoria. El estudio de patología reportó una lesión benigna de configuración polipoide, revestida por epitelio escamoso maduro, descansando en un estroma laxo, finamente vascularizado, con áreas de ulceración.

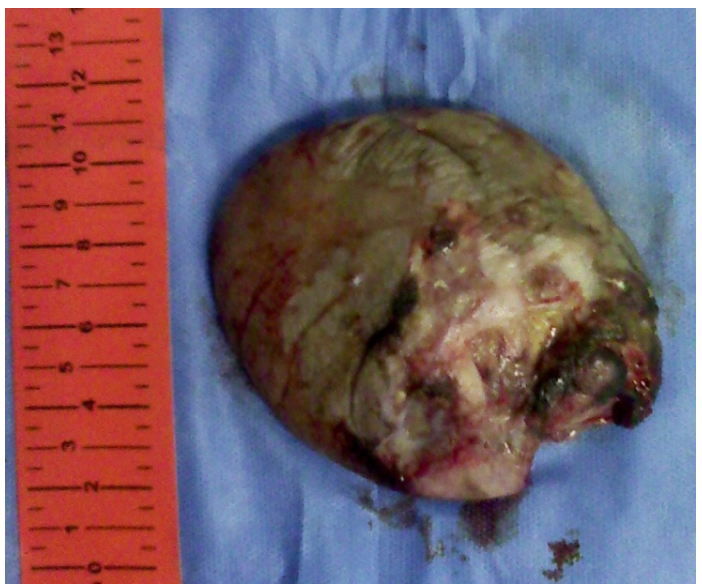

Figura $\mathbf{N}^{\circ} \mathbf{2}$. Masa de pigmentación uniforme. Áreas de ulceración y bordes necróticos con secreción serosa y purulenta en el extremo distal.

\section{DISCUSIÓN}

El AC también llamado pólipo fibroepitelial o skin tags, es una lesión poliposa benigna conformada por tejido fibrovascular y dermis. Pediculada y de tallo estrecho. Tiene incidencia de $46.0 \%$ y afecta por igual a hombres y mujeres en la edad adulta y aumenta la prevalencia con el incremento en la edad (1).

Se ha reportado tendencia familiar para este tipo de lesiones, los pacientes con enfermedad de Crohn suelen tener AC en región perianal. También se han encontrado asociados a pólipos del colon, pero es controversial el hecho (2) y se ha descrito que aparecen o crecen durante el segundo trimestre del embarazo para regresar o incluso desaparecer en el posparto, probablemente por efectos del influjo hormonal de la gestación (3).

Se consideran factores de riesgo para la presencia de AC la obesidad, dislipidemia y antecedentes de diabetes mellitus. En estos pacientes es posible encontrar múltiples lesiones simultáneas $(5,6)$.

Los AC se localizan en zonas de pliegues corporales, las más frecuentes son axila, cuello, pliegue submamario y en la región inguinal $(2-6)$.

El cuadro clínico del AC está caracterizado por la aparición de una lesión asintomática de pigmentación uniforme, pequeña y de lento crecimiento, en raras ocasiones alcanza los cinco centímetros. Son lesiones pedunculadas que pueden retorcerse produciendo: edema, isquemia y necrosis por reducción del retorno venoso. Cuando se encuentra la lesión complicada con torsión y necrosis, su coloración normocrómica cambia a violácea o negra. Como su localización más común son los pliegues cutáneos, la fricción en esta zona y la torsión parcial aumentan el riesgo de necrosis y sobreinfección (3).

El diagnóstico del AC se basa en las características clínicas de la lesión y se confirma con el estudio histológico, donde se observa estroma fibrovascular con colágeno y tejido fibroso, pudiendo existir reacción inflamatoria crónica y presencia de epitelio queratinizante grueso (4).

Si bien no es típica la ubicación en la región vulvar, cuando se identifica se deben realizar diagnóstico diferenciales con lesiones malignas como el carcinoma basocelular, espinocelular y con el neurofibroma. También se deben tener presente diversas lesiones infecciosas. Cuando el $A C$ es muy pequeño puede confundirse con una lesión causada por el virus de papiloma humano. Si no se realiza tratamiento oportuno de las lesiones pequeñas, pueden llegar a tener grandes tamaños, como el caso presentado, situaciones en las cuales es mayor la posibilidad de ulceración e infección secundaria.

Todas las lesiones sugestivas de AC deben ser resecadas y las piezas enviadas a estu- 
dio patológico. El tratamiento definitivo es la resección de la lesión ya sea excisional o con cauterización, dependiendo del tamaño y la localización de la lesión.

\section{CONCLUSIÓN}

El AC es una patología benigna, pocas veces asentada en la vulva. Usualmente asintomáticos, pero puede llegar a grandes tamaños con mayor riesgo de ulceraciones e infec- ción. Toda lesión una vez diagnosticada debe ser retirada.

CONFLICTOS DE INTERESES: ninguno que declarar.

FINANCIACIÓN: recursos propios de los autores. Atención clínica, material quirúrgico, insumos hospitalarios, gastos clínicos y honorarios profesionales cubiertos en la atención asistencial.

\section{REFERENCIAS BIBLIOGRÁFICAS}

1. Kassinove A, Raam R. Acrochordon of the labia. J Emerg Med. 2013;44(5):e361-2.

2. Gould BE, Ellison RC, Greene HL, Bernhard JD. Lack of association between skin tags and colon polyps in a primary care setting. Arch Intern Med. 1988;148:1799.

3. Winton GB, Lewis CW. Dermatoses of pregnancy. J Am Acad Dermatol 1982; 6:977.

4. Wilkinson EJ, Stone IK. Atlas of vulvar disease. Philadelphia: Lippincott; 2008, p. 105-6.

5. Tamega Ade A, Aranha AM, Guiotoku MM, Miot LD, Miot HA. Association between skin tags and insulin resistance. An Bras Dermatol. 2010;85(1):25-31.

6. Rasi A, Soltani-Arabshahi R, Shahbazi N. Skin tag as a cutaneous marker for impaired carbohydrate metabolism: a case-control study. Int J Dermatol. 2007; 46(11):1155-59.

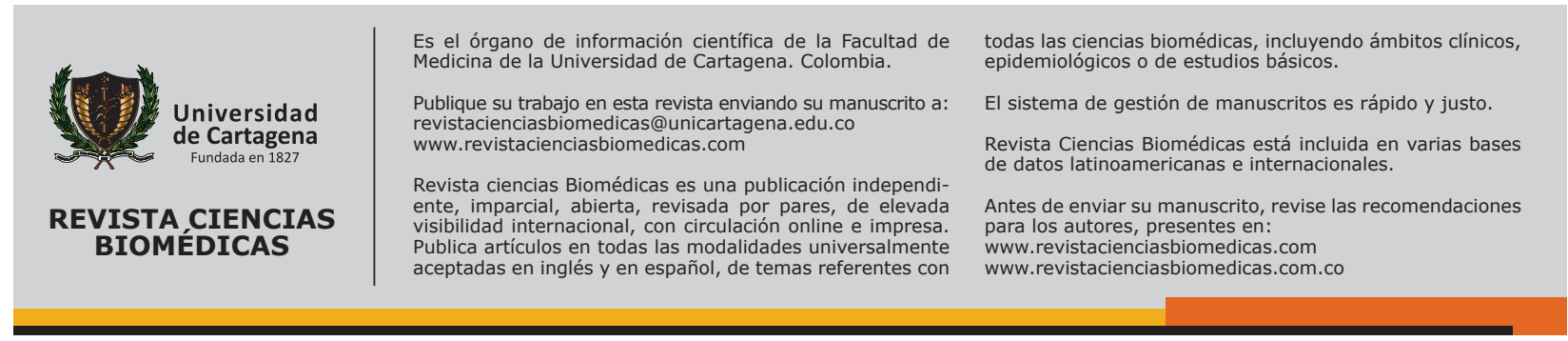

